\title{
Faceting Behavior of Primary Ag in Bi-Ag Alloys for High Temperature Soldering Applications
}

\author{
Jenn-Ming Song* and Hsin-Yi Chuang \\ Department of Materials Science and Engineering, National Dong Hwa University, Hualien 974, Taiwan, R.O. China
}

The solidification behavior and structure of Bi-Ag alloys with low Ag content ( 0 mass \% 11 mass \%) which are now being applied as high temperature $\mathrm{Pb}$-free solders were investigated. The results show that $\mathrm{Bi}$ - $\mathrm{Ag}$ alloys exhibited a nonequilibrium eutectic solidification feature and a considerably large undercooling. A longer cooling period to reach eutectic temperature enhanced the faceting of primary Ag crystals. The large value of the entropy of solution for Ag near the eutectic point should account for this. [doi:10.2320/matertrans.M2009089]

(Received March 9, 2009; Accepted April 1, 2009; Published June 25, 2009)

Keywords: Bismuth-Silver, microstructure, faceting behavior, thermal properties

\section{Introduction}

Eutectic Bi-Ag (as indicated in Fig. 1, the eutectic temperature is $262.5^{\circ} \mathrm{C}$ at the eutectic composition, $\mathrm{Bi}$ $2.5 \mathrm{mass} \% \mathrm{Ag}$ ) is one of the important systems for investigating the characterization of eutectic structures because it shows a faceted $(\mathrm{Ag}) /$ non-faceted $(\mathrm{Bi})$ type structure and an anomalous broken lamellar appearance. ${ }^{1)}$ Primary Ag phase in $\mathrm{Ag}$ rich $\mathrm{Bi}-\mathrm{Ag}$ alloys with the $\mathrm{Ag}$ content of 14.7 mass\% (25 at\%) and above (34.0 mass\% and 82.3 mass\%) has been studied by Ojha et al. ${ }^{2)}$ They suggested that instead of $\Delta S$ (the entropy of solution) and $\alpha$ (roughness parameter, $\Delta S / R$ ), the temperature dependence of entropy of solution $(d \Delta S / d T)$ governs the growth morphology of primary Ag. A related equation proposed by Saroch et al. is given as follows: ${ }^{3)}$

$$
\frac{d \Delta S^{\alpha \mathrm{L}}}{d T}=\frac{1}{m_{\alpha}} \frac{\partial \Delta S^{\alpha \mathrm{L}}}{\partial x_{\mathrm{e}}^{\alpha}}+\frac{1}{m_{\mathrm{L}}} \frac{\partial \Delta S^{\alpha \mathrm{L}}}{\partial x_{\mathrm{e}}^{\mathrm{L}}}
$$

where $\Delta S^{\alpha \mathrm{L}}$ represents the entropy difference between $\alpha$ and the liquid from which it is growing. $m_{\alpha}$ and $m_{\mathrm{L}}$ are the slopes of solidus and liquidus, and $x_{\mathrm{e}}^{\alpha}$ and $x_{\mathrm{e}}^{\mathrm{L}}$ are equilibrium compositions of the primary phase and of the liquid ahead of the solid-liquid interface, respectively.

Since the Bi-Ag system shows retrograde solid solubility (i.e. $m_{\alpha}$ is very large), the slope of liquidus curve, $m_{\mathrm{L}}$, dominates the variation of $(d \Delta S / d T)$ and thus determine if the primary Ag is faceted or not. ${ }^{2}$ Unfortunately, there is still a lack of observations on the primary $\mathrm{Ag}$ phase of $\mathrm{Bi}-\mathrm{Ag}$ alloys with the Ag content less than 14.7 mass\%.

Recently, low Ag Bi-Ag alloys attracted much interest and have been considered as the replacement for high $\mathrm{Pb}$ solders for high temperature applications to die attach solders for power devices and LEDs, ${ }^{4-6)}$ because they exhibit an acceptable melting point, similar hardness to that of $\mathrm{Pb}-5 \mathrm{Sn}$, and affordable cost. It has been demonstrated that raising the $\mathrm{Ag}$ content from the eutectic composition (2.5 mass\%) to 11 mass $\%$ promotes the increase in thermal conductivity and the electrical conductivity, as well as good ductility even under high deformation rates. ${ }^{5,7)}$ All those improvements could be ascribed to the formation of primary Ag. Consid-

*Corresponding author, E-mail: samsong@mail.ndhu.edu.tw

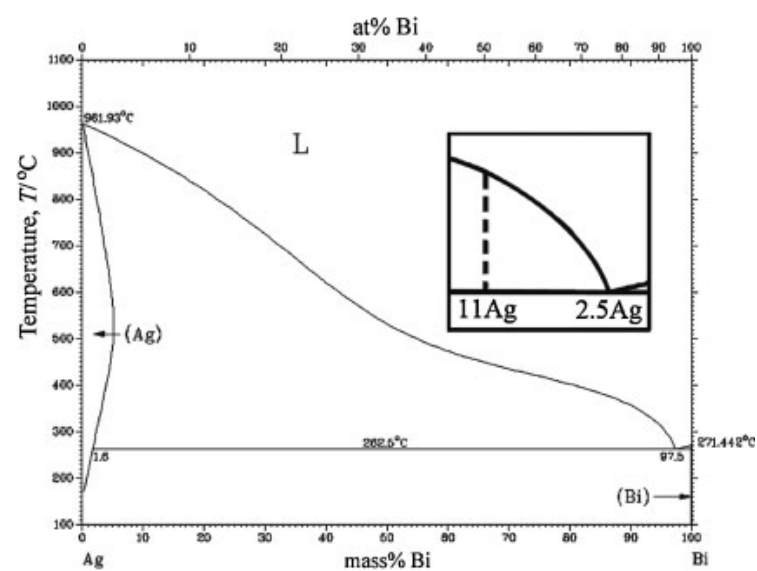

Fig. 1 Ag-Bi binary phase diagram.

ering that the morphology of dispersoids like primary $\mathrm{Ag}$ may strongly influence the mechanical performance, the faceting behavior of the primary $\mathrm{Ag}$ of low $\mathrm{Ag} \mathrm{Bi}-\mathrm{Ag}$ alloys needs to be clarified.

\section{Experiments}

$\mathrm{Bi}-\mathrm{Ag}$ alloys with the Ag content of 2.5 mass\% (eutectic composition) and 11 mass $\%$, (hypereutectic composition) designated as $\mathrm{Bi}-2.5 \mathrm{Ag}$ and $\mathrm{Bi}-11 \mathrm{Ag}$ respectively, were prepared by melting pure bismuth and pure silver in an arc melting furnace in an argon atmosphere. Pure Bi samples were also prepared for comparison. The thermal behavior of the alloys was investigated using DSC (Differential Scanning Calorimetry) analysis. The specimens with the weight of $100 \mathrm{mg}$ were heated to above $400^{\circ} \mathrm{C}$ and then cooled to the ambient temperature, with a constant rate of $1^{\circ} \mathrm{C} / \mathrm{min}$ (referred to as slowly-cooled samples, SC) or $15^{\circ} \mathrm{C} / \mathrm{min}$ (rapidly-cooled samples, RC).

\section{Results and Discussion}

Figure 2 illustrates the representative DSC curves of the $\mathrm{Bi}-11 \mathrm{Ag}$ samples measured at $1^{\circ} \mathrm{C} / \mathrm{min}$ or $15^{\circ} \mathrm{C}$ heating/ cooling rate and the results of all the samples are listed in 


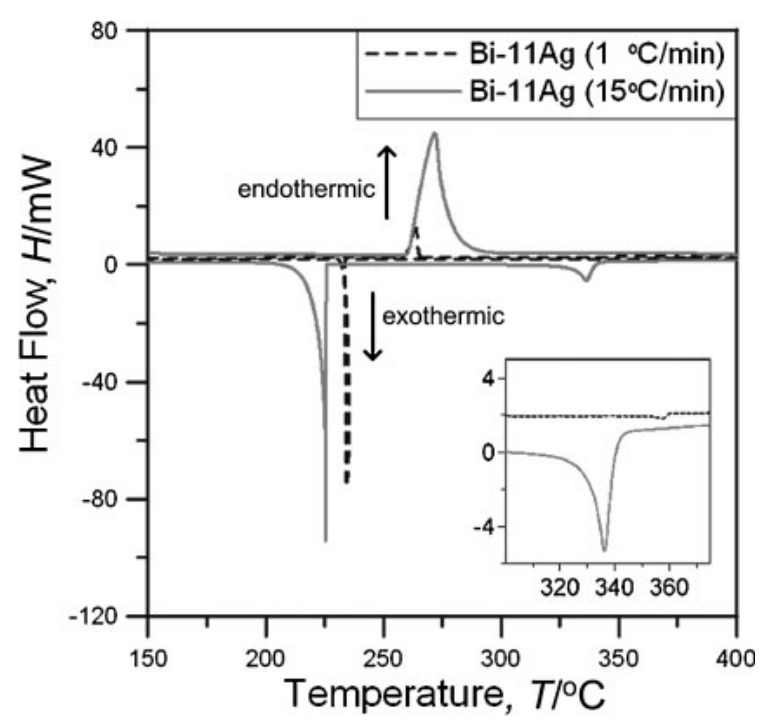

Fig. 2 DSC analysis results of the Bi-11Ag under heating/cooling rates of $1^{\circ} \mathrm{C} / \mathrm{min}(\mathrm{SC})$ and $15^{\circ} \mathrm{C} / \mathrm{min}(\mathrm{RC})$ respectively.

Table 1 Specific temperatures $\left({ }^{\circ} \mathrm{C}\right)$ of the DSC results under different testing conditions. $T_{\mathrm{p}}$-endo and $T_{\mathrm{p}}$-exo are ultimate temperature values of the endothermic peaks upon heating and exothermic peaks upon cooling. Their difference represents the degree of undercooling $(\Delta T)$.

\begin{tabular}{lcccc}
\hline Sample (condition) & $\begin{array}{c}T_{\mathrm{P}} \text {-endo } \\
\text { (eutectic) }\end{array}$ & $\begin{array}{c}T_{\mathrm{P}} \text {-exo } \\
\text { (eutectic) }\end{array}$ & $\begin{array}{c}\Delta T \\
\text { (eutectic) }\end{array}$ & $\begin{array}{c}T_{\mathrm{p}} \text {-exo } \\
(\mathrm{P}-\mathrm{Ag})\end{array}$ \\
\hline Pure Bi $\left(1^{\circ} \mathrm{C} / \mathrm{min}\right)$ & 271.2 & 231.2 & 40.0 & - \\
Pure Bi $\left(15^{\circ} \mathrm{C} / \mathrm{min}\right)$ & 280.2 & 223.7 & 56.5 & - \\
\hline $\mathrm{Bi}-2.5 \mathrm{Ag}\left(1^{\circ} \mathrm{C} / \mathrm{min}\right)$ & 263.3 & 230.7 & 32.6 & - \\
$\mathrm{Bi}-2.5 \mathrm{Ag}\left(15^{\circ} \mathrm{C} / \mathrm{min}\right)$ & 275.5 & 227.0 & 48.5 & - \\
\hline $\mathrm{Bi}-11 \mathrm{Ag}\left(1^{\circ} \mathrm{C} / \mathrm{min}\right)$ & 263.8 & 231.9 & 31.9 & 357.0 \\
$\mathrm{Bi}-11 \mathrm{Ag}\left(15^{\circ} \mathrm{C} / \mathrm{min}\right)$ & 271.7 & 225.6 & 46.1 & 336.0 \\
\hline
\end{tabular}

Table 1. Upon heating, the temperatures of the endothermal peaks for the eutectic reaction did not differ too much at the same heating rate and that for fusion of pure Bi was slightly higher than the others. Due to undercooling, the exothermic peaks upon cooling for all the samples appeared at a lower temperature compared to their endothermal peak. The degree of undercooling, obtained from the difference in peak temperature between endothermic and exothermal reactions decreased in turn from pure $\mathrm{Bi}, \mathrm{Bi}-2.5 \mathrm{Ag}$ and then $\mathrm{Bi}-11 \mathrm{Ag}$. However, the lowest undercooling measured in this study, $31.9^{\circ} \mathrm{C}$ for the $\mathrm{Bi}-11 \mathrm{Ag}$ sample, is still tremendous. This can be ascribed to the rhombohedral structure of Bi because a large supercooling can be obtained for metals having a more complex crystal structure including $\mathrm{Sn}, \mathrm{Bi}, \mathrm{Ga}$ and the like. ${ }^{8)}$ In addition, a small exothermic peak was detected in the DSC curve of the Bi-11Ag upon cooling (as indicated in the bottom insert in Fig. 2, $336^{\circ} \mathrm{C}$ for $\mathrm{RC}$ and $357^{\circ} \mathrm{C}$ for SC). This exothermal behavior was due to the crystallization of the primary Ag phase in the melt.

Figure 3 illustrates the microstructure of the $\mathrm{Bi}-2.5 \mathrm{Ag}$ pellets subsequent to remelting and cooling. As for the RC samples, eutectic cells comprising extremely fine Ag-rich nodules could be observed (Figs. 3(a) and (b)). A small number of Bi grains also appeared (Fig. 3(b)), implying that $\mathrm{Bi}-\mathrm{Ag}$ is a nonequilibrium eutectic system and the eutectic

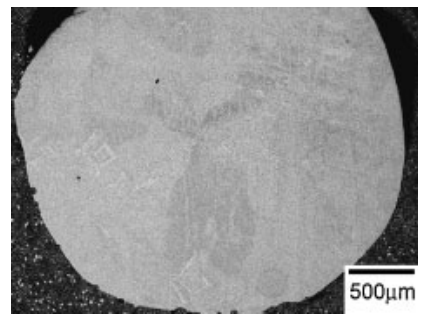

(a)

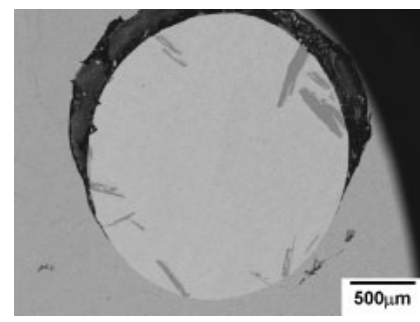

(c)

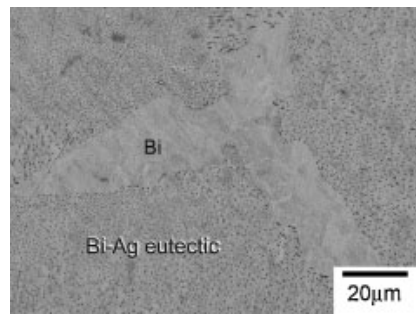

(b)

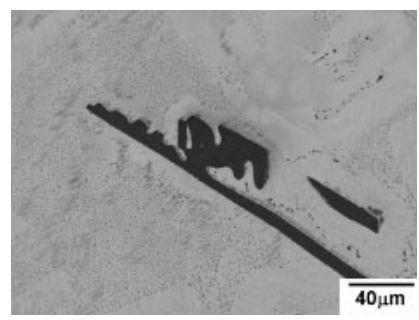

(d)
Fig. 3 Cross-sectional structure of (a) $\mathrm{RC} \mathrm{Bi}-2.5 \mathrm{Ag}$ and (b) magnified microstructure in (a); (c) SC Bi-2.5Ag solder balls and (d) magnified image of primary $\mathrm{Ag}$ in (c).

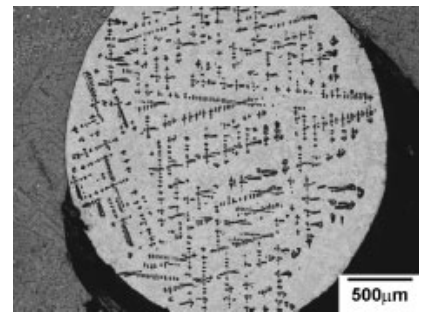

(a)

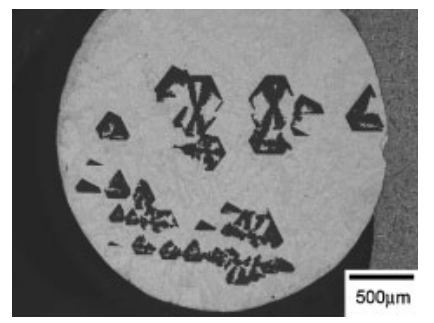

(c)

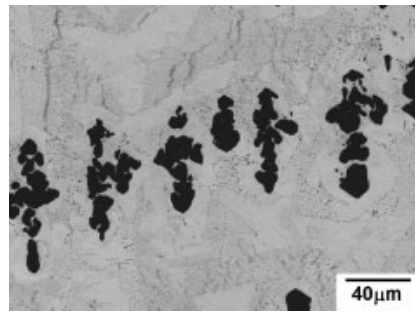

(b)

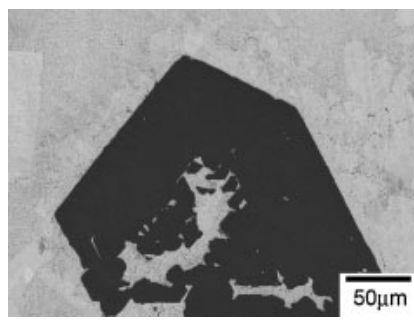

(d)
Fig. 4 Microstructure of Bi-11Ag alloys: (a), (b) the RC samples and (c), (d) the SC samples.

composition was shifted towards $\mathrm{Ag}$ side. Interestingly, in the case of SC samples, Figs. 3(c) and (d), some large Ag plates with long flat interfaces and one end attached to the surface of the pellet could be found. It can be deduced that the pellet surface might act as a heterogeneous nucleation site for primary Ag plates.

Figure 4 displays the morphology of primary Ag in the Bi$11 \mathrm{Ag}$ pellets under different cooling conditions. In the RC samples, fine Ag dendrites with round shape were distributed in arrays. On the other hand, the primary Ag in the SC pellets was substantially enlarged in size and showed internal branching and faceted contours. As aforementioned, the faceting of primary Ag in high Ag alloys was suggested to be determined by $(d \Delta S / d T)$, or simply by the slope of liquidus curve. A less steep slop leads to a greater $(d \Delta S / d T)$ and thus results in a faceted growth. Also, Ojha et al. ${ }^{2)}$ suggested that 


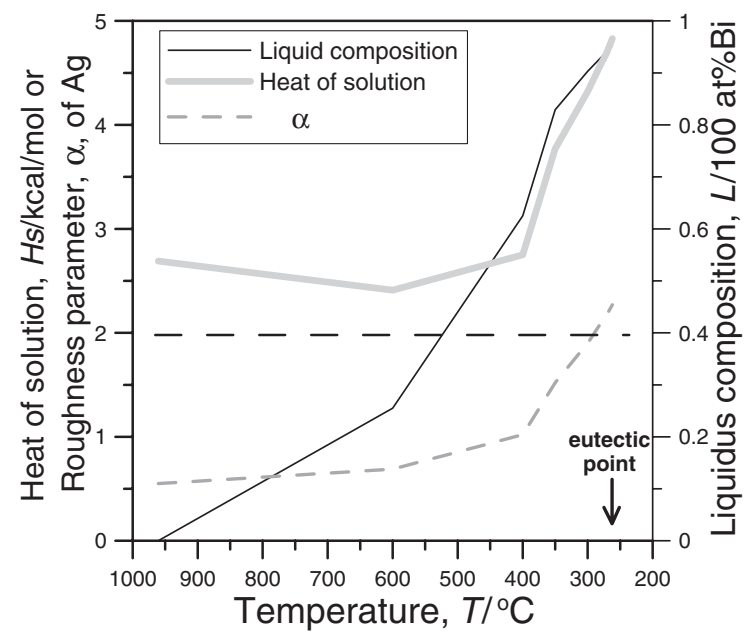

Fig. 5 The relationships between thermodynamic properties, liquid composition and temperature (based on M. R. Taylor et al. ${ }^{9}$ ).

the primary Ag develops a tendency to become nonfaceted subjected to a slow cooling. Those are not identical with the observation in this study. Regardless of the steep slope of liquidus curve for $\mathrm{Ag}$ near the eutectic point (as illustrated in the inserted diagram in Fig. 1), the faceted primary $\mathrm{Ag}$ formed and appeared only in slowed cooled samples.

The thermodynamic data given in Fig. 5 could interpret our findings. ${ }^{9)}$ The heat of solution for $\mathrm{Ag}$ is raised drastically as the liquid temperature is lower than $400^{\circ} \mathrm{C}$. This leads to an increase in the entropy of solution and also a greater roughness parameter $(\alpha)$ which exceeds 2.0 (meets so called $\alpha$-factor criterion proposed by Jackson ${ }^{10)}$ ) when the liquid temperature drops below $300^{\circ} \mathrm{C}$. Accordingly, it can be inferred that as for slow-cooled $\mathrm{Bi}-2.5 \mathrm{Ag}$ samples primary $\mathrm{Ag}$ crystallized at temperatures very close to eutectic point $\left(262.5^{\circ} \mathrm{C}\right)$ and thus it grew into faceted plates. With respect to the slow-cooled $\mathrm{Bi}-11 \mathrm{Ag}$ samples, primary phase started to crystallize at around $350^{\circ} \mathrm{C}$ based on our results in Fig. 2 so it might be nonfaceted at the early stage of solidification. Upon subsequent crystallization at temperatures below $300^{\circ} \mathrm{C}$, slow cooling allowed $\mathrm{Ag}$ atoms from the liquid attached to the Ag crystals laterally and formed faceted contours. In the case of rapidly-cooled $\mathrm{Bi}-11 \mathrm{Ag}$, solidification period between $300^{\circ} \mathrm{C}$ and the eutectic point was very short, so the Ag crystals remained nonfaceted and showed a round morphology after all.

\section{Conclusions}

In short, low $\mathrm{Ag} \mathrm{Bi}-\mathrm{Ag}$ alloys exhibit characteristics of nonequilibrium eutectic solidification feature, large undercooling and faceted primary Ag under slow cooling conditions. The entropy of solution $(\Delta S)$, rather than $d \Delta S / d T)$, is considered as the most influential factor dominating faceting behavior for the alloys with near eutectic composition. A longer solidification period through the temperature region just above eutectic point contributes to a more faceted primary Ag.

\section{Acknowledgments}

This work has been supported by the National Science Council of R.O.C. (Contract: NSC 95-2216-E-259-001), for which the authors are grateful.

\section{REFERENCES}

1) M. N. Crocker, R. S. Fidler and R. W. Smith: Proc. Roy. Soc. London A 335 (1973) 15-37.

2) S. N. Ojha and R. K. Mandal: J. Mater. Sci. Lett. 15 (1996) 326-328.

3) M. Saroch, K. S. Dubey and P. Ramachandrarao: J. Cryst. Grow. 126 (1993) 701-706.

4) L. N. Lalena, N. F. Dean and M. W. Weiser: J. Electron. Mater. 31 (2002) 1244-1249.

5) J. H. Kim, S. W. Jeong and H. M. Lee: Mater. Trans. 43 (2002) 18731878.

6) M. Rettenmayr, P. Lambracht, B. Kempf and M. Graff: Adv. Eng. Mater. 7 (2005) 965-969.

7) J. M. Song, H. Y. Chuang and T. X. Wen: Metall. Mater. Trans. A 38 (2007) 1371-1375.

8) Fundamentals of Physical Metallurgy, (John Wiley and Sons, Inc., NY, 1975) p. 233.

9) M. R. Taylor, R. S. Fidler and R. W. Smith: Metall. Trans. 2 (1971) 1793-1798.

10) K. A. Jackson: J. Cryst. Growth 3 (1968) 507-517. 